\title{
Juan José Saer: la imagen de lo indecible
}

\section{Florencia Amorena}

\section{OpenEdition}

\section{Journals}

Edición electrónica

URL: https://journals.openedition.org/cher/12361

DOI: 10.4000/cher.12361

ISSN: 2803-5992

\section{Editor}

Presses universitaires de Strasbourg

\section{Edición impresa}

Fecha de publicación: 30 junio 2012

Paginación: 181-189

ISBN: 978-2-35410-046-9

ISSN: 1968-035X

\section{Referencia electrónica}

Florencia Amorena, «Juan José Saer: la imagen de lo indecible», reCHERches [En línea], 8 | 2012, Publicado el 21 febrero 2022, consultado el 23 febrero 2022. URL: http://journals.openedition.org/ cher/12361 ; DOI: https://doi.org/10.4000/cher.12361

\section{c) (i) (2)}

Ce(tte) œuvre est mise à disposition selon les termes de la Licence Creative Commons Attribution Pas d'Utilisation Commerciale - Partage dans les Mêmes Conditions 4.0 International. 


\section{Juan José Saer: la imagen de lo indecible}

FLORENCIA AMORENA

Université Paris 8, Vincennes-Saint Denis / Université de Tours

\section{Introducción: Saer y la crítica, los dos caminos}

Los distintos caminos que ha tomado la crítica para analizar la obra de Juan José Saer son múltiples. Entre ellos hay dos que presentarían una aparente paradoja: por un lado el cuestionamiento de su vínculo con el realismo decimonónico y por el otro el de la autorreferencialidad del texto. Es decir, hay una contradicción entre una literatura que se preocupa por la realidad que se encuentra más allá del texto, de la experiencia y otra que reflexiona sobre sí misma y los límites de la forma.

Hay, sin embargo una explicación en dicha contradicción: la primera etapa de la obra saeriana que incluiría sus tres primeros libros de cuentos y sus dos primeras novelas se caracteriza por la posesión de ciertos tintes realistas. Así, por ejemplo en su primera novela, Responso, se relata el derrumbe del personaje central, Barrios, ligado a la caída de Perón y al mismo tiempo en el cuerpo del texto se vislumbraría una cierta preocupación formal: en Saer la política aparece, como afirma Luppi, «como bajo continuo, inserta en sus producciones literarias de manera diversa y novedosa, en mayor o menor medida según los momentos, frecuentemente con la carga de tensiones vinculadas al peronismo» (Luppi 2005). En varios casos, lo político también está acompañado por elementos sociales que remiten a una sociedad burguesa. Lo cierto es que si bien lo político y lo social han estado presentes, siguiendo la evolución de su obra podemos observar que la narrativa saeriana, sobre todo a partir de su segunda etapa, enfatiza su preocupación 
por una escritura que se cuestiona acerca de sus límites, que se preocupa por la percepción y su capacidad de narrar la realidad que aprehende y otorgarle un sentido. Estos dos caminos, si bien presentados como independientes permitirían, como sugiere Rafael Arce, una iluminación mutua.

\section{El fracaso como punto de partida}

La noción de fracaso tal y como fue utilizada en la literatura occidental durante los siglos XIX y XX permitiría tal vez unir ambos recorridos para, en consecuencia, reflexionar acerca del programa literario saeriano.

En el caso del realismo decimonónico en la literatura europea, se presenta bajo dos formas, por un lado, la del fracaso a causa de una condición social determinada y, por el otro, la del fracaso debido a la inepcia del personaje. En el primero caso Le rouge et le noir es una obra representativa en tanto que Julien Sorel es quebrado por un entorno social que no deja lugar al genio, mientras que en el segundo L'éducation sentimentale es el ejemplo ilustrativo ya que pone en evidencia la impericia de Frederick Moreau: «un héros sans héroïsme, figure emblématique de ce que la modernité appellera anti-héros, un roman de formation devenu le modèle du roman de l'échec, l'histoire d'un jeune homme spectateur d'une Histoire qui ne fait pas sens» (Leclerc 1997: 5).

Más adelante, en el siglo XX, la noción de fracaso ligada a un proyecto literario va de la mano de escritores como Beckett, que afirmaba «the expression that there is nothing to express, nothing with which to express, nothing from which to express, no power to express, no desire to express, together with the obligation to express» (Beckett 1976: 103). Se trata de una literatura que, aunque no tenga nada que decir, ni ninguna realidad desde donde decir, siempre se verá obligada a decir, incluso en los momentos en que habrá perdido la fe o el deseo de narrar.

\section{Fracaso político y fracaso estético}

A partir de las definiciones expuestas, y repensando un poco el camino de la crítica saeriana, cabe preguntarse si acaso se podrían utilizar al servicio de una lectura sobre el programa literario saeriano.

En otras palabras, si bien es cierto que el vínculo con el realismo se debilita a partir de la etapa más experimental de la obra saeriana y la de su madurez fundándose sobre todo en un distanciamiento y en una marca de contraste, 
existe la posibilidad de pensar que algunos rasgos del fracaso en la literatura del siglo XIX podrían servir como punto de partida para luego avanzar sobre el problema estético en Saer. Con esta idea presente me propongo hacer un recorrido de la noción del fracaso en dos de sus novelas Glosa (1985) y La grande (2005) partiendo de su representación en la novela decimonónica para luego avanzar hacia la del siglo XX y ver si en la complementariedad de ambas se construye un hilo conductor que acerque a la lectura de un programa estético en donde, paradójicamente, el fracaso sería justamente la realización misma de un programa literario en el sentido en el que lo entiende Cioran: «Exister s'épuise dans le plaisir de ne pas penser. Être un objet qui regarde; un point, c'est tout» (Cioran 1997: 170). Un programa literario que ante la pregunta de qué narrar, cómo narrar en lugar de dar una fórmula definitiva va a buscar una respuesta en una fórmula abierta que ponga el acento en el movimiento continuo de la narración.

Glosa es una novela organizada en tres partes que relatan una caminata que comparten Leto y el Matemático durante una mañana de octubre de 1962. Si bien a primera vista la conversación parece transcurrir en un tono relativamente liviano, a medida que el lector avanza en el relato es testigo de recuerdos de los personajes, pensamientos e incluso flash forwards que van revelando elementos claves de su vida. Sobre esta superficie "cordial", el lector se entera que Leto, joven contable de 20 años, ha perdido a su padre a causa de un suicidio ocurrido hace pocos meses o que Washington Noriega ha pasado varios años en un psiquiátrico durante el peronismo dejando abierta la posibilidad de que la causa de su reclusión en realidad haya sido política.

La voz narradora teje un entramado de recuerdos y pensamientos configurando un contenido que la mayor parte de las veces nace de la mente de los dos personajes durante su caminata.

Por un lado, nos encontramos con Leto, que como ya dijimos, ha perdido a su padre meses antes. Si bien es un joven que en apariencia se ha integrado a su nueva vida y círculo de amigos, hay algo sobre "el rol" que representa que no lo termina de convencer. Como si no terminara de creer que el lugar que ocupa fuera el verdadero, el que realmente le corresponde. Así, por ejemplo, por más que Leto se reafirme mentalmente que si bien nadie lo invitó a la fiesta de Washington Noriega porque en realidad él no necesita invitación, cierra su reflexión con la afirmación que en definitiva, él no fue a la fiesta porque simplemente no lo invitaron. En cuanto al Matemático, nos encontramos con un joven que si bien reniega de sus orígenes burgueses es 
un claro símbolo de joven exitoso. Se ha graduado de ingeniero químico y acaba de llegar de un viaje a Europa que hizo con los recién graduados de la universidad:

$\mathrm{Su}$ aspecto físico, perfeccionado por el bronceado europeo y por la blancura de su vestimenta, no es otra cosa que la consecuencia de sus perfecciones biográficas: a pesar de haber sido una de las estrellas del equipo de rugby del club universitario tiene, según la expresión de Tomatis, algo un poco más denso en la cabeza que lo que suelen tener adentro, una vez infladas, las pelotas de rugby (Saer 1985: 26).

Sin embargo, a pesar de toda esta perfección, hay algo en él que le produce malestar. Así, hay dos hechos que sobresalen en la novela y que son en gran parte causa de dicho malestar. Por un lado la necesidad u obsesión de alcanzar siempre la perfección en cuanto a sus conocimientos intelectuales como si nunca fuera a ser suficiente y nunca podría estar al mismo nivel de discusión que Tomatis:

El Matemático, que tal vez presiente, en la reserva dicharachera de Tomatis, el escepticismo o la desconfianza; sigue impasible en el papel que se ha asignado: el de aportar, sin que, en verdad, nadie se lo haya pedido por no haber notado su ausencia, el rigor lógico en las discusiones y una exactitud en la información que, por su insistencia, termina resultando molesta (26-27).

El otro hecho en donde se ve con claridad el sentimiento de no pertenecer es lo que el mismo Matemático llama «el episodio». Durante todo un mes había preparado un texto sobre una «teoría de la versificación» y debía discutirlo con un importante poeta que venía de Buenos Aires y con el que se escribía asiduamente hacía varios meses. Finalmente, llegado el momento del encuentro, el Matemático debe ausentarse de la conferencia que daba el poeta pero asegura volver enseguida y pide a todos que lo esperen antes de ir a cenar. Cuando regresa se da cuenta que nadie lo ha esperado, se encuentra solo y con un sentimiento de rabia y humillación: «en realidad, la actitud inesperada del poeta lo había dejado sin capacidad de reacción, como si su vida interior funcionara a electricidad y, desde hacía dos o tres minutos, alguien hubiese venido desde la oscuridad y lo hubiese desenchufado» (35). La sensación de desconectarse del mundo del poeta, al cual él debía pertenecer, es evidente. El fracaso del sujeto marginado se ve en la desazón que siente al saber que forma parte de aquellos seres que, por más que lo intenten, no "pertenecerán” a ese mundo: «un sentimiento nuevo se mezclaba a su humillación y a su rabia: la desesperación que sentimos cuando comprobamos que, por intenso que sea nuestro deseo, los planes de lo exterior no lo tienen en cuenta» (37). Y con la sensación de fracaso 
empieza la fragmentación del individuo en la sociedad a la que debería pertenecer:

El Matemático empezó a sentir que la persona que creía ser se desmantelaba pieza por pieza, y en su lugar flotaban a la deriva las astillas y fragmentos de un ente desconocido que tenían, con un propio ser, un aire de familia, pero parecían, respecto de las ideas, emociones y sentimientos habituales, arcaicos y desmesurados (38).

Está claro que en el Matemático hay una clara división entre una exterioridad aparentemente perfecta y bien consolidada y una interioridad fragmentada que de una forma u otra se irá prolongando a lo largo de su vida. No es casual que años después el papel con el poema de Tomatis, más allá de su contenido que no deja de ser sugerente, funcionara como un amuleto que le permitiría mantener un cierto orden o equilibrio entre esos «fragmentos heterogéneos del universo» (127).

Además del fracaso del individuo en la sociedad, tanto Leto como el Matemático serán en el futuro víctimas de un sistema político que forzará al primero al suicidio y al segundo al exilio. Así Leto, convertido en militante político abandonará su trabajo y el lugar que ocupaba en la sociedad para pasar a la clandestinidad y finalmente toma la pastilla de veneno al encontrarse sin escapatoria:

Habiéndose dado cuenta al cabo de quince años que luchar a ciegas contra la opresión puede engendrar más opresión en lugar de acabar con ella, del mismo modo que ciertos métodos para combatir un incendio contribuyen más bien a acrecentar las fuerzas de las llamas, y habiendo llegado demasiado lejos como para dar marcha atrás, empezará a confiar, no en estrategias, ni en organizaciones, ni en sacudimientos históricos, como los llaman, ni siquiera en su propia ametralladora, sino únicamente en la pastilla, en su pastilla (225).

Si bien se puede pensar que el suicidio es un éxito en tanto que el militante no traiciona a su grupo, en el caso de Leto queda claro que el discurso de «sacrificio, patria y victoria» no es el que lo lleva al suicidio. Descreído de cualquier ideología su suicidio no pretende ni traicionar ni dar su vida en nombre de una lucha específica sino reforzar una idea de clausura en donde después de ella no quedará, irremediablemente, nada. De esta forma la pastilla de veneno será «no una prueba de omnipotencia ante sus enemigos, sino [...] una razón de burla y de desprecio, detrás de su cara impasible, ante sus propios aliados» (22). Se tratará, entonces, de una falta de confianza en la posibilidad efectiva de cambiar la realidad, de un fracaso político. 
Además de la importancia de esto episodios en cuanto a la trama, Glosa es una novela que privilegia el problema de la narración de la memoria y de la percepción de la realidad. Es, lo ha dicho ya reiteradas veces la crítica, una novela que «se afirma todavía más en su actividad contemplativa, disectora, rumiante de una realidad [...]» (Corbatta 1999: 105) y que se pregunta si acaso es posible obtener la versión definitiva y "real" de un evento. La reconstrucción del relato de la fiesta de cumpleaños de Washington Noriega a la que ni el Matemático ni Leto asistieron sería un signo de esta imposibilidad. Ya el comienzo, dubitativo acerca de la fecha exacta de la caminata nos instaura en una narración dudosa. Luego, más adelante en el relato la voz narradora alude a esa distancia de la representación en relación con lo "real": cuando Leto debe "corregir" la imagen que tiene de Botón, personaje a quien nunca ha visto, pero que cuando es nombrado por el Matemático se lo representa con una imagen que luego deberá cambiar:

El Matemático no vacila en poner en la balanza, como se dice, defectos y virtudes de Botón, para gran contrariedad de Leto, que debe corregir la imagen un poco sumaria que ha venido elaborando; para él se trataba de un entrerriano morocho, picado de viruelas, estudiante de abogacía, más afecto al vino y a la guitarra que a los apuntes de Derecho Civil, violador aficionado en sus ratos libres, más bien populachero en sus gustos literarios, de inteligencia un poco obtusa, y ahora resulta que se trata de un muchacho exquisito, protector del arte de vanguardia, una especie de santo, capaz del más grande de los sacrificios - mantenerse sobrio - si un fin superior - es la expresión que se utiliza en estos casos - se lo exige" (Saer 1985: 187).

Vemos entonces que en la narración de la caminata lo que se observa es un movimiento, que está dado como afirma Rafael Arce, no solamente por la caminata en sí y por el recorrido espacial de esas veintiuna cuadras sino también por una descomposición temporal, por la duda, la incertidumbre con respecto a lo narrado: «Lo real es en Saer algo que depende no de la información ni de la descripción ni del conocimiento, sino de la eclosión». Como bien nos lo recuerda Arce en nombre de la crítica saeriana: «estas narraciones ponen en evidencia la imposibilidad de todo conocimiento».

El caso de La grande, también puede ser analizado desde estas dos nociones de fracaso, la del individuo y su relación con la sociedad y aquella que se vincula con lo estético. Publicada en el año 2005 aunque hubiera quedado inconclusa, está estructurada en siete capítulos y cada uno tiene por título un día de la semana y un subtítulo. La narración está principalmente en presente y se centra en torno al personaje de Guillermo Gutiérrez, un guionista que tras un exilio de casi treinta años vuelve a su ciudad natal, 
compra una casa y, aparentemente, desea retomar la vida que ha dejado. Las razones por las que se ha marchado se remontan a sus 24 años. En ese entonces se había enamorado de Leonor Calcagno, una mujer casada con un importante abogado de la zona. Tras haber tenido una breve relación con ella, decidieron huir juntos, pero a último momento ella se arrepiente y le pide a él que desaparezca. Casi treinta años después Leonor lo vuelve a ver en Europa y le dice que la hija que tuvo es suya y no de su ya difunto marido. A pesar de lo dudoso de esta afirmación, Gutiérrez, que quiere creer más que nadie, vuelve para retomar la relación con ella y conocer a su hija Lucía. A partir de esta historia central se narrarán otras historias como las de Nula, el vendedor de vinos, su esposa, Lucía, la chica de la que estuvo enamorado hace cinco años y que estaba casada, Gabriela Barco, Tomatis y la de Brando, la cabeza del movimiento precisionista que ha tenido su momento de apogeo también hace treinta años. Así como hay varias versiones sobre la fiesta de cumpleaños en Glosa encontramos un procedimiento similar en tanto que Nula se va armando distintas versiones sobre la causa del regreso de Gutiérrez.

Ante este nostos el lector se configura una imagen del que regresa que se condice con la de aquel que quiere recuperar la familiaridad perdida, como si el tiempo no hubiera pasado. Para esto "interpreta" el rol de alguien que pertenece a ese lugar determinado, que es parte del espacio en el que se mueve, de la misma manera que lo han hecho el Matemático armándose de un conglomerado de lecturas que habilitará su participación en discusiones intelectuales. Pero el retorno de Gutiérrez definitivamente no es un regreso épico, al contrario, debe ser construido con hechos, gestos, palabras que lo llevarán no de regreso a la patria perdida sino a un viaje que contendrá un misterio impenetrable, para el que no hay palabras, ni gestos que logren develar su verdadera esencia. Así se referirá el narrador en relatar el encuentro entre Gutiérrez y su amigo Escalante al que ve por primera vez después de 30 años de exilio:

Las décadas de la vida empírica que transcurridos separados son sin duda un misterio impenetrable y recíproco del que, aunque pasen el resto de sus vidas refiriéndoselas mutuamente, no conseguirán poseer más que una serie de fragmentos heteróclitos y vagos. A Nula se le ocurre que, en este momento por lo menos, esas décadas de vida empírica no les interesan: lo único que parecen desear es rencontrar el flujo de la vida en común que el tiempo, las distancias y las vicisitudes ya abolidas de sus existencias respectivas habían arrumbado en ese limbo en el que ahora, intercambiando frases irónicas 
y lentas, pero que arrastran consigo vestigios verídicos de información, poniendo entre paréntesis lo exterior intentan reunirse (Saer 2005: 49).

El fracaso del nostos, si bien marca claramente la distancia con respecto a todo rasgo realista tiene también su punto de contacto con él: el escenario sobre el que se compone la intriga del regreso se funda en lo que Arce llama «una crudeza del material novelesco [...] hay demasiada "historia", demasiada "realidad" [que] se debe a [una] apertura de la narración saeriana al material social».

Pero ante esta apertura sigue estando subyacente la pregunta del programa saeriano: qué narrar, cómo narrar. Y es en esta novela, con un largo llamativamente mayor al de las otras novelas de Saer, donde se vuelve al intento de respuesta. Si el fracaso estético va de la mano de la imposibilidad de aprehender la realidad y expresarla, en tanto que no se puede dar un sentido definitorio a lo real a través de la literatura, lo que ésta sí puede hacer es poner en evidencia la necesidad de insistir en la narración en tanto constante creación y movimiento. De ahí que la narración saeriana privilegie tanto el tiempo presente y la idea de movimiento, que ya mencionamos en Glosa y a la que en La grande se sigue aludiendo e incluso de una forma más fuerte ya que se insiste en la necesidad de narrar privilegiando la mirada del presente.

Hay si se quiere una "narración de la imagen", una "visualización del texto" en donde se articula ese vínculo entre literatura y realidad, un vínculo que está lejos de cristalizarse en definiciones o procedimientos. Si la imagen fija de la realidad es un fracaso en tanto que es imposible dar cuenta de algo que está en cambio constante y que depende de la percepción, la propuesta de La grande es narrar una imagen en infinitas posibilidades. Es en este sentido que está claramente marcado el límite entre lo que es la descripción de una fotografía o un hecho del pasado en la novela, en donde se va la artificialidad o la economía de la narración, como si el narrador supiera de antemano que los fragmentos del pasado nunca podrán dar cuenta de una totalidad; mientras que las narraciones del presente aunque se muestran fragmentarias parecen encontrar su éxito siendo una mera posibilidad de hacer legible la mirada, una posibilidad de ser un punto que simplemente mira.

Ante el fracaso de modificar la realidad o "formar parte de ella" (el suicidio de Leto, el exilio del Matemático o el regreso de Gutiérrez), la narración nos muestra una visión del mundo que parecería presentarse como un fracaso estético en tanto que no puede darle un sentido definitivo a lo real como lo intentaría el género de la novela, pero en ese fracaso se inscribe un proyecto 
de escritura basado simplemente en mostrar los límites de la ficción y hacer de él un éxito.

Volvemos entonces a la idea del inicio mencionada a través de la cita de Beckett que funda la escritura en ese sentimiento de obligación de escribir. Leto, sin saber por qué se seguirá acordando «casi veinte años después de los mosquitos de Washington [porque para] el Leto guerrillero, esos mosquitos son más reales que la irrealidad de la acción política». Ese "volver" a narrar para sí que hace Leto del relato de la fiesta será imagen cifrada de la escritura y en su necesidad misma de expresar se fundará su condición de existencia. Del mismo modo la cita de Cioran ahora llevada al ámbito propio de la literatura permite concluir que no se trata de otorgar sentido sino de asumir que su existencia consiste sobre todo en ser un punto que mira, nada más y que en esta resignación está el éxito.

\section{Bibliografía}

Arce, Rafael, «La pasión de lo real», in Cuadernos del seminario 2. Realismos, Rosario, Centro de Estudios de Literatura Argentina, en prensa.

Beckett, Samuel, 1976, Proust and three dialogues with Georges Duthuit, London, J. Calder, p. 5-17.

Cioran, 1997, Cahiers 1957-1972, Paris, Gallimard.

Corbatta, Jorgelina, 1999, Narrativas de la guerra sucia (Piglia, Saer, Valenzuela, Puig), Buenos Aires.

Leclerc, Yoan, 1997, «Etudes littéraires» in L'éducation sentimentale, Paris, PUF.

Luppi, Juan Pablo, 2005, «Ese oscuro objeto de deseo. Las zonas marginales de J.J. Saer y M. Puig en el campo cultural argentino de fines de los 60»: http:// programamesa2.blogspot.com/2005/10/ese-oscuro-objeto-de-deseo-las-zonas. html

Saer, Juan José, 2005, La grande, Buenos Aires, Seix Barral.

Saer, Juan José,1985, Glosa, Buenos Aires, Seix Barral. 